Steroid therapy in an alpha-dystroglycanopathy due to GMPPB gene mutations : A case report

Fecarotta, S.

2018-11

Fecarotta , S, Gragnaniello , V , Della Casa , R , Romano , A, Raiano , E, Torella , A , Savarese , M , Nigro , V , Strisciuglio , P , Andria , G \& Parenti , G 2018 , ' Steroid therapy in an alpha-dystroglycanopathy due to GMPPB gene mutations : A case report ' , Neuromuscular Disorders, vol. 28 , no. 11 , pp. 956-960 . https://doi.org/10.1016/j.nmd.2018.07.001

http://hdl.handle.net/10138/308864

https://doi.org/10.1016/j.nmd.2018.07.001

publishedVersion

Downloaded from Helda, University of Helsinki institutional repository.

This is an electronic reprint of the original article.

This reprint may differ from the original in pagination and typographic detail.

Please cite the original version. 


\title{
Steroid therapy in an alpha-dystroglycanopathy due to GMPPB gene mutations: A case report
}

\author{
S. Fecarotta ${ }^{a}$, V. Gragnaniello ${ }^{a}$, R. Della Casa ${ }^{a}$, A. Romano ${ }^{a}$, E. Raiano ${ }^{b}$, A. Torella ${ }^{c, d}$, \\ M. Savarese ${ }^{\mathrm{c}, \mathrm{e}}$, V. Nigro ${ }^{\mathrm{c}, \mathrm{d}}$, P. Strisciuglio ${ }^{\mathrm{a}}$, G. Andria ${ }^{\mathrm{a}}$, G. Parenti ${ }^{\mathrm{a}, \mathrm{d}, *}$ \\ ${ }^{a}$ Department of Translational Medical Sciences, Federico II University, Naples, Italy \\ ${ }^{\mathrm{b}}$ Department of Public Health, Rehabilitation Unit, Federico II University, Naples, Italy \\ ${ }^{\mathrm{c}}$ Department of Precision Medicine, University of Campania 'Luigi Vanvitelli', Naples, Italy \\ ${ }^{\mathrm{d}}$ Telethon Institute of Genetics and Medicine, Pozzuoli, Italy \\ ${ }^{\mathrm{e}}$ Folkhälsan Research Center, Medicum, University of Helsinki, Helsinki, Finland
}

Received 1 June 2018; received in revised form 4 July 2018; accepted 10 July 2018

\begin{abstract}
Alpha-dystroglycanopathies are a group of progressive and untreatable neuromuscular disorders, due to aberrant alpha-dystroglycan glycosylation. We describe the effects of a short-term cycle of corticosteroid therapy in a 9-year-old boy, affected by an alpha-dystroglycanopathy due to $G M P P B$ gene mutations. The patient was affected by a congenital progressive muscular dystrophy since the first month of life, associated with psychomotor delay, seizures, and congenital bilateral cataracts. Despite physical therapy he had a progressive motor impairment. At the age of 9 years, he was treated with $0.75 \mathrm{mg} / \mathrm{kg} /$ day of prednisone for 3 months and showed improvements in muscle strength and function scores and creatine kinase reduction. When steroid therapy was discontinued he showed again clinical and biochemical deterioration. These data suggest that corticosteroid may be considered as a treatment for patients with alpha-dystroglycanopathies due to $G M P P B$ mutations.

(C) 2018 Elsevier B.V. All rights reserved.
\end{abstract}

Keywords: GMPPB; Alpha-dystroglycanopathy; Congenital muscular dystrophy; Corticosteroid therapy.

\section{Introduction}

Alpha-dystroglycanopathies are a genetically and clinically heterogeneous group of neuromuscular disorders, due to aberrant alpha-dystroglycan glycosylation. Dystroglycan is a protein complex composed of alpha and beta subunits, and is an essential link between the extracellular matrix and the actin-associated cytoskeleton, especially in muscle tissues. This complex plays a fundamental role in the development and maintenance of basement membranes, in neuronal migration, and in neuromuscular junction formation. Alphadystroglycan posttranslational glycosylation is critical for its

\footnotetext{
* Corresponding author at: Giancarlo Parenti, Department of Translational Medical Sciences, Section of Pediatrics, Federico II University, Via S. Pansini 5, Naples 80131, Italy and Telethon Institute of Genetics and Medicine, Via Campi Flegrei 34, Pozzuoli, Italy.

E-mail addresses: parenti@tigem.it, parenti@unina.it (G. Parenti).
}

function [1]. To date, mutations in 21 genes have been associated with defective alpha-dystroglycan glycosylation. Among these, GMPPB encodes an enzyme (GDP-mannose pyrophosphorylase B) that catalyses the formation of GDP-mannose, required for O-mannosylation of alpha-dystroglycan. $G M P P B$ mutations have been described so far in about 50 cases. The phenotypic spectrum is broad, including severe congenital muscular dystrophy (CMD) associated with brain and eye abnormalities and intellectual disability (i.e. Walker-Warburg syndrome, muscle-eye-brain disease, and Fukuyama congenital muscular dystrophy), severe congenital muscular dystrophy with absent or mild brain involvement (MDC1C and MDC1D), milder forms of late onset limb-girdle muscular dystrophies (LGMD2I and LGMD2K) [2], and a congenital myasthenic syndrome [3]. The disease course is generally progressive. Although in the myasthenic presentations some benefits have been obtained with pyridostigmine and salbutamol, to date there is no effective therapy available for other 
phenotypes [1]. Here, we describe the effects of a short-term cycle of prednisone therapy in a patient affected by GMPPB alpha-dystroglycanopathy.

\section{Case report}

The patient, a 9 years and 6 months old boy of nonconsanguineous parents, was first referred to our hospital at the age of 6 months because of microcephaly, hypotonia, elevated serum creatine kinase $(\mathrm{CK})$, psychomotor delay, seizures, and congenital bilateral cataracts. At the age of 7 months cataracts were treated surgically, with residual modest increase in eye pressure. The diagnosis of alphadystroglycanopathy was based on muscle histology, performed at the age of 4 years, showing a dystrophic pattern with reduced alpha-dystroglycan, and on the molecular analysis of the GMPPB gene that showed compound heterozygosity for the p.Q234* and p.T153I mutations.

During follow-up psychomotor delay became progressively more evident, with independent ambulation acquired at 4 years of age. Since the age of 8 years, the patient presented a rapid deterioration in functional abilities, and at the age of 9 years he could sit and hold up his head unsupported only for short periods; he was able to stand and walk only for short distances; he could not roll, climb or descend stairs, and was unable to rise from the floor or stand up from a chair without support. On physical examination, he showed axial and proximal weakness with a predominant involvement of the lower limb. He had mild intellectual disability $(\mathrm{IQ}=10-25$ percentile with Raven matrix).

At two different occasions, the parents reported on transient improvements of muscle strength and motor activity after the administration of oral steroids for intercurrent respiratory infections. On one of these occasions a reduction of serum CK levels to $405 \mathrm{U} / \mathrm{L}$ was also documented, compared to average $\mathrm{CK}$ values in the last 5 years of $1650 \mathrm{U} / 1$ (range 814-5082 U/L). Based on this information and after approval by the ethics committee and informed consent from parents, when the patient was 9 years old we started a 3-month trial with $0.75 \mathrm{mg} / \mathrm{kg} /$ day oral prednisone, according to the treatment protocol for Duchenne muscular dystrophy (DMD) [4]. The patient was evaluated monthly by clinical examination, laboratory tests, muscle strength scale (Medical Research Council-MRC) and motor function scales (motor function measure-MFM, Vignos and Brooke), already validated for other muscular dystrophies such as DMD [5,6]. Despite the presence of mild intellectual disability, the patient was collaborative and compliant with all tests. During treatment serum CK significantly decreased (Fig. 1, Supplementary Table S1) and the patient showed improvements of motor function evaluated by Vignos and Brooke rating scale (Fig. 2a, Supplementary Table S2a) and by MFM (Fig. 2b, Supplementary Table S2b) and of muscle strength evaluated by MRC (Fig. 3, Supplementary Table S3). At the end of the trial he had re-

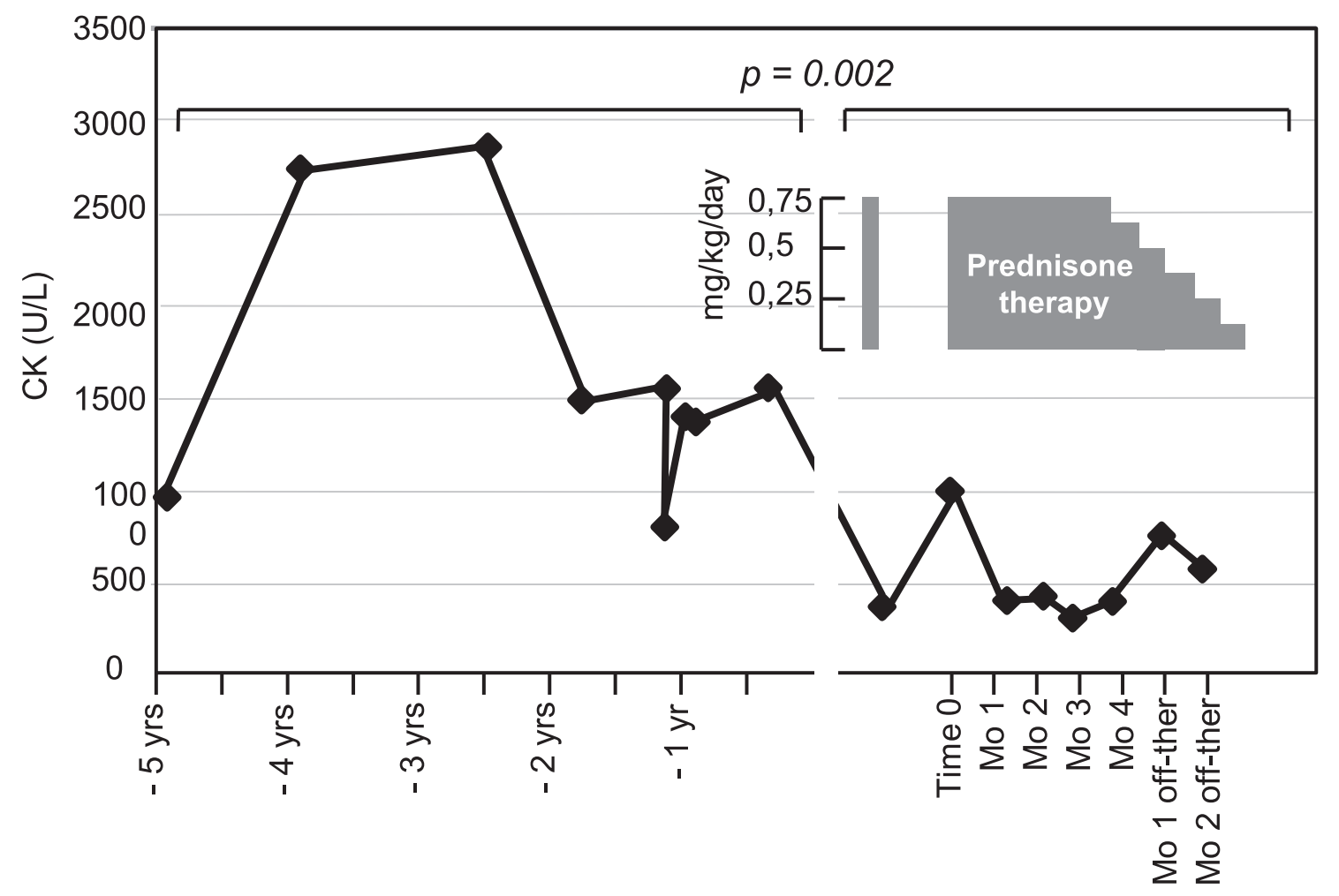

Fig. 1. Changes in serum CK levels before, during and after corticosteroid treatment.

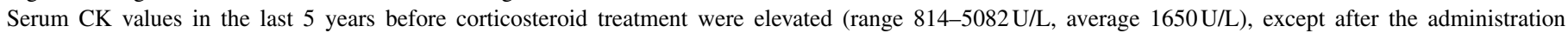

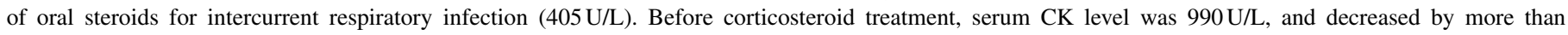

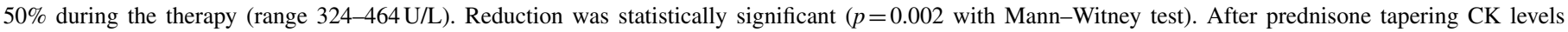
increased again. 


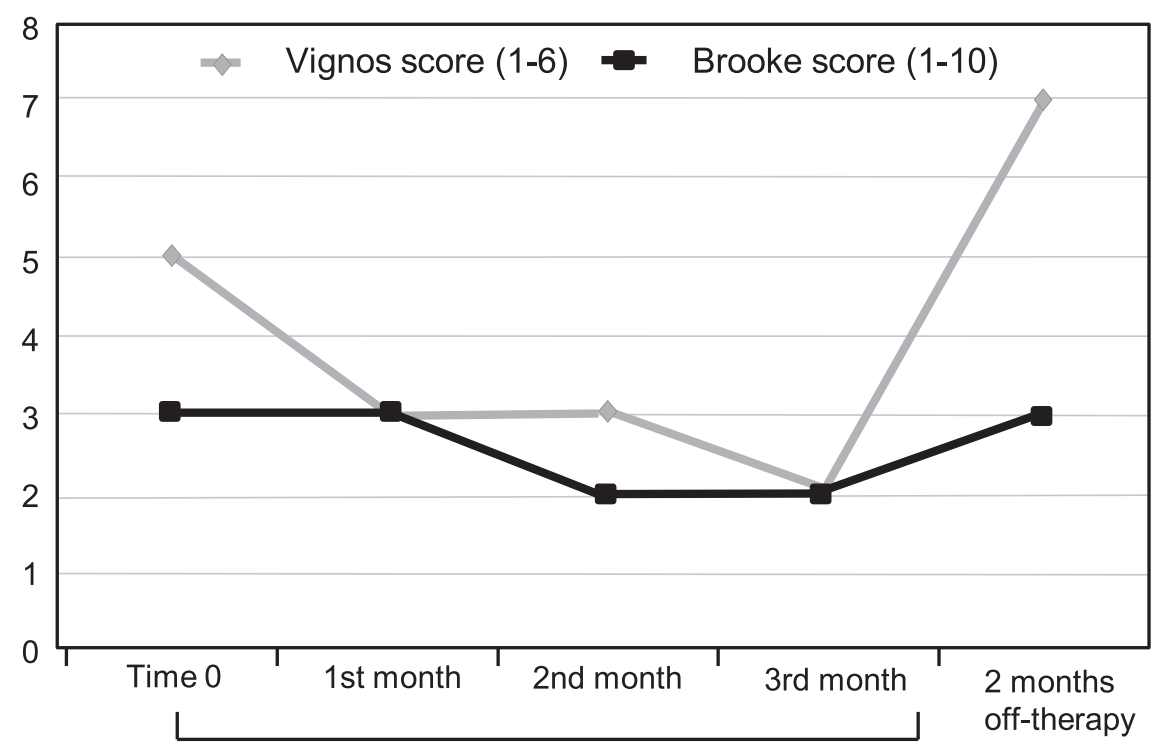

Prednisone therapy

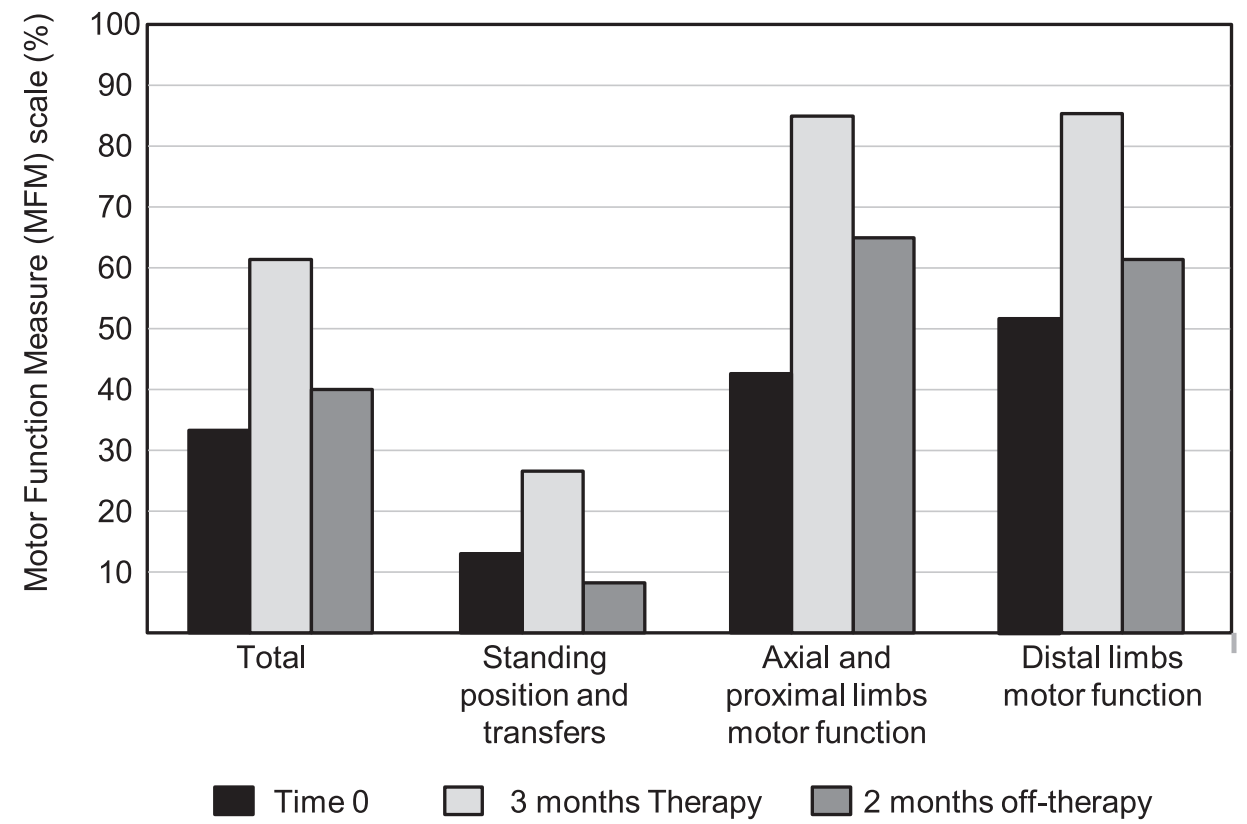

Fig. 2. Changes in motor function scores before, during and after corticosteroid treatment.

(a) Values of Vignos and Brooke score. (b) Motor function measure (MFM) scale. Vignos score and MFM showed an improvement, especially for lower limbs, during corticosteroid treatment and a worsening after their discontinuation. Brooke score remained unchanged.

gained the ability to stand and walk independently, although only for short distances, and showed improved trunk and head control; he could rise his arms above his head, roll and rise from sitting to standing position with minimal support. Possible undesired effects (hyperglycemia, hypertension, bone loss, excessive weight gain) were closely monitored. Only a modest weight gain $(2 \mathrm{~kg})$ was observed. The patient did not experience infections, sleep/behavior or gastrointestinal problems. Cardiac examination remained normal. On ophthalmic examination, however, a further increase of intraocular pressure was documented, thus prednisone therapy was gradually tapered $(-2.5 \mathrm{mg}$ every 2 weeks) and discontinued over 3 months. Prednisone decalage and discontinuation resulted in resumption of disease manifestation, with deterioration of muscle strength (Fig. 3, Supplementary Table S3) and a drop in function score (Fig. 2a, b, Supplementary Table S2a, b). Serum CK levels increased (Fig. 1, Supplementary Table S1). Remarkably, already after 1 month of prednisone decalage, at 


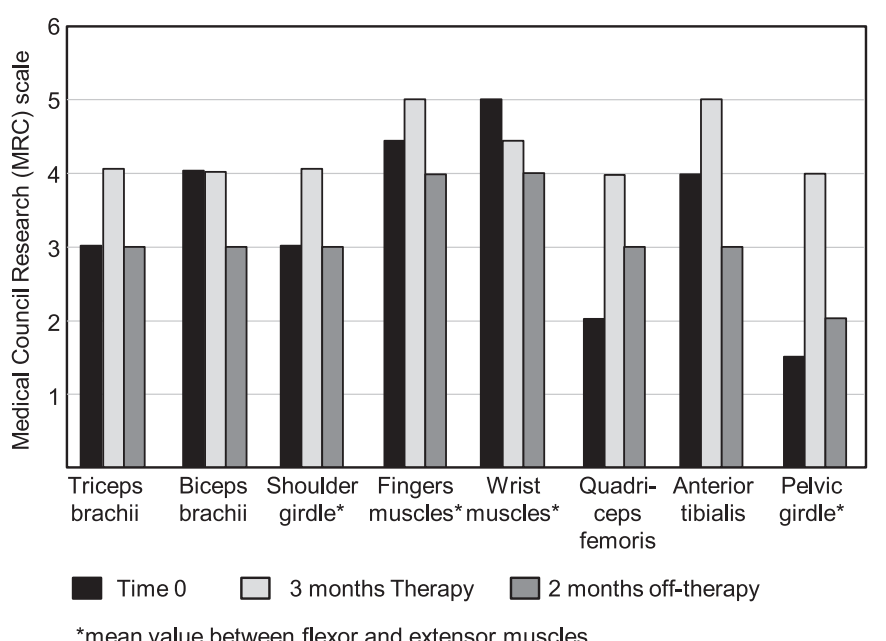

Fig. 3. Changes in muscular strength score before, during and after corticosteroid treatment.

Medical Research Council (MRC) scale showed an improvement during corticosteroid treatment and a worsening after their discontinuation.

a dosage of $0.5 \mathrm{mg} / \mathrm{kg} / \mathrm{day}$, the patient had lost the ability to walk even with support and to rise from sitting to a standing position. At the end of decalage he lost the ability to stand without support and he could control head and trunk in the sitting position only for a few minutes.

\section{Discussion}

Corticosteroid treatment is known to slow the decline in muscle strength and function in DMD, in which it is now one of the mainstays in the treatment [4]. The mechanisms underlying its effect are not completely clear, likely due to an anabolic effect on myoblast proliferation and muscle regeneration, and to the ability to reduce muscle necrosis and inflammation [7-10]. Efficacy of corticosteroid treatment in muscular dystrophies other than DMD has not been formally proven. A few anecdotal reports indicated that corticosteroid treatment also improved motor abilities in dystroglycanopathies, such as FKRP (Fukutin-related protein) muscular dystrophy. A study in a murine experimental model of LGMD 2I carrying the FKRP p.P448L mutation demonstrated that corticosteroids, alone or in combination with alendronate, enhance functionally glycosylated alpha-dystroglycan, improve muscle pathology and alleviate the dystrophic phenotype [11]. Godfrey et al. and Darin et al. reported on five LGMD patients with FKRP mutations, erroneously diagnosed as affected by polymyositis (two cases) or DMD (three cases) and treated with steroids, that showed a remarkable clinical response to this treatment $[12,13]$.

Based on these literature data we tested the effects of prednisone in our patient, using the same therapeutic regimen that is in use for DMD [4]. The results of this short-term trial were encouraging.

On prednisone treatment our patient showed improvements in tests that evaluate motor function, with regain of some motor skills, and muscle strength, and significant decrease in CK levels. Improvements in muscle strength and function were more evident in the lower limbs, probably because they were initially more compromised. The resumed rapid deterioration of muscle strength and motor functions experienced by the patients when prednisone was discontinued further supports the efficacy of corticosteroid treatment. Albeit anecdotal and based on a single case report, our experience suggests that corticosteroids may be considered to treat other patients with alpha-dystroglycanopathies due to GMPPB mutations and with rapidly progressive impairment of motor function.

This research did not receive any specific grant from funding agencies in the public, commercial, or not-for-profit sectors.

\section{Supplementary materials}

Supplementary material associated with this article can be found, in the online version, at doi:10.1016/j.nmd.2018.07. 001.

\section{References}

[1] Taniguchi-Ikeda M, Morioka I, Iijima K, Toda T. Mechanistic aspects of the formation of $\alpha$-dystroglycan and therapeutic research for the treatment of $\alpha$-dystroglycanopathy: a review. Mol Aspects Med 2016;51:115-24.

[2] Carss KJ, Stevens E, Foley AR, Cirak S, Riemersma M, Torelli S, et al. Mutations in GDP-mannose pyrophosphorylase B cause congenital and limb-girdle muscular dystrophies associated with hypoglycosylation of $\alpha$-dystroglycan. Am J Hum Genet 2013;93(1):29-41.

[3] Belaya K, Rodriguez Cruz PM, Liu WW, Maxwell S, McGowan S, Farrugia ME, et al. Mutations in GMPPB cause congenital myasthenic syndrome and bridge myasthenic disorders with dystroglycanopathies. Brain 2015;138:2493-504.

[4] Bushby K, Finkel R, Birnkrant DJ, Case LE, Clemens PR, Cripe L, et al. Diagnosis and management of Duchenne muscular dystrophy, part 1: diagnosis, and pharmacological and psychosocial management. Lancet Neurol 2010;9(1):77-93.

[5] Lu YM, Lue YJ. Strength and functional measurement for patients with muscular dystrophy. Muscular dystrophy. Hegde M, editor InTechChapter 17. Available from; 2012.

[6] Berard C, Payan C, Hodgkinson I, Fermanian JMFM Collaborative Study Group. A motor function measure scale for neuromuscular diseases. Construction and validation study. Neuromuscul Disord 2005; 15:463-70.

[7] Pasquini F, Guerin C, Blake D, Davies K, Karpati G, Holland P. The effect of glucocorticoids on the accumulation of utrophin by cultured normal and dystrophic human skeletal muscle satellite cells. Neuromuscul Disord 1995;5(2):105-14.

[8] Rifai Z, Welle S, Moxley RT 3rd, Lorenson M, Griggs RC. Effect of prednisone on protein metabolism in Duchenne dystrophy. Am J Physiol 1995;268(1 Pt 1):E67-74.

[9] Sklar RM, Brown RH Jr. Methylprednisolone increases dystrophin levels by inhibiting myotube death during myogenesis of normal human muscle in vitro. J Neurol Sci 1991;101(1):73-81.

[10] Spuler S, Engel AG. Unexpected sarcolemmal complement membrane attack complex deposits on non-necrotic muscle fibers in muscular dystrophies. Neurology 1998;50(1):41-6.

[11] Wu B, Shah SN, Lu P, Richardson SM, Bollinger LE, Blaeser A, et al. Glucocorticoid steroid and alendronate treatment alleviates dystrophic phenotype with enhanced functional glycosylation of $\alpha$-dystroglycan in mouse model of limb-girdle muscular dystrophy with FKRPP448L mutation. Am J Pathol 2016;186(6):1635-48. 
[12] Darin N, Kroksmark AK, Ahlander AC, Moslemi AR, Oldfors A, Tulinius M. Inflammation and response to steroid treatment in limbgirdle muscular dystrophy 2I. Eur J Paediatr Neurol 2007;11(6):353357.
[13] Godfrey C, Escolar D, Brockington M, Clement EM, Mein R Jimenez-Mallebrera C, et al. Fukutin gene mutations in steroid-responsive limb girdle muscular dystrophy. Ann Neurol 2006;60(5):603610. 